\title{
Hypoxia Increases Human Keratinocyte Motility on Connective Tissue
}

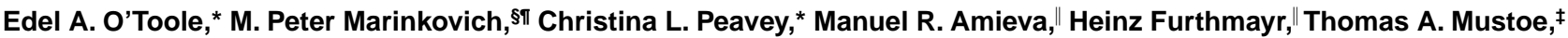 \\ and David T. Woodley* \\ *Department of Dermatology and ${ }^{\ddagger}$ Division of Plastic Surgery, Northwestern University Medical School, Chicago, Illinois 60611; \\ ${ }^{\S}$ Department of Dermatology and ${ }^{\|}$Department of Pathology, Stanford University, Stanford, California 94305; and ${ }^{\mathbb{T}}$ Dermatology Service, \\ VA Palo Alto Health Care System, Palo Alto, California 94304
}

\begin{abstract}
Re-epithelialization of skin wounds depends upon the migration of keratinocytes from the cut margins of the wound and is enhanced when human keratinocytes are covered with occlusive dressings that induce hypoxia. In this study, two independent migration assays were used to compare cellular motility on connective tissue components under normoxic or hypoxic conditions. Human keratinocytes apposed to collagens or fibronectin exhibited increased motility when subjected to hypoxic ( 0.2 or $2 \%$ oxygen) conditions compared with normoxic (9 or $20 \%$ oxygen) conditions. When compared with normoxic cells, hypoxic keratinocytes exhibited increased expression and redistribution of the lamellipodia-associated proteins (ezrin, radixin, and moesin). Furthermore, hypoxic keratinocytes demonstrated decreased secretion of laminin-5, a laminin isoform known to inhibit keratinocyte motility. Hypoxia did not alter the number of integrin receptors on the cell surface, but did induce enhanced secretion of the 92-kD type IV collagenase. These data demonstrate that hypoxia promotes human keratinocyte motility on connective tissue. Hypoxia-driven motility is associated with increased expression of lamellipodia proteins, increased expression of collagenase and decreased expression of laminin-5, the locomotion brake for keratinocytes. (J. Clin. Invest. 1997. 100: 2881-2891.) Key words: re-epithelialization • integrins • laminin-5 • collagenase $\cdot$ cytoskeleton
\end{abstract}

\section{Introduction}

Conventional wisdom is that the provision of significant oxygen is necessary for proper healing of skin wounds $(1,2)$. Elderly individuals with ischemic vascular disease and poor perfusion to their lower extremities are frequently plagued by skin ulceration and poor healing. Tissue oxygen measurements have been used to study the effect of oxygen on healing wounds. Noninvasive measurements using transcutaneous oximetry and Laser doppler flowmetry clearly indicate that the degree

This work was presented as a paper at the Annual Meeting of the Society for Investigative Dermatology held in Chicago, Illinois, 26 May 1995.

Address correspondence to David T. Woodley, M.D., Department of Dermatology, Northwestern University Medical School, 4-711 Tarry Building, Chicago, IL 60611. Phone: 312-908-1989; FAX: 312908-1984; E-mail: eba290@nwu.edu

Received for publication 6 November 1996 and accepted in revised form 14 October 1997.

The Journal of Clinical Investigation

Volume 100, Number 11, December 1997, 2881-2891

http://www.jci.org of tissue ischemia correlates with poor healing (3-5). Hyperbaric oxygen chambers have been built at great expense and used for the treatment of nonhealing wounds (6). Nevertheless, sometimes venous ulcers heal even when the transcutaneous oxygen pressure is markedly reduced (7).

One major advancement in the healing of cutaneous wounds is the use of semiocclusive dressings (hydrogels, hydrocolloids, and polyurethane membranes). These dressings promote re-epithelialization and wound closure compared with wounds allowed to air-dry (8-12), but must be used early after wounding to induce rapid re-epithelialization in vivo (13). Wounds allowed to air-dry have oxygen tensions between $1-4 \%$ at the surface where keratinocytes are migrating $(4,14)$. In contrast, under occlusive dressings, the $\mathrm{pH}$ is very low and the oxygen tension is almost negligible (15). Yet, these dressings clearly promote re-epithelialization compared with wounds allowed to air-dry that have a higher oxygen tension at the wound surface.

Wound healing is a complex phenomenon that has several distinct components including coagulation, re-epithelialization, angiogenesis, fibroplasia, contraction, and remodeling (16). It is conceivable that each of these processes may have distinct responses to microenvironmental factors such as hypoxia. Reepithelialization is the process by which the keratinocytes migrate horizontally from the wound margins across the wound bed and resurface the wound with an epithelium. Keratinocyte motility is an early event in the process of re-epithelialization (16). We have had experience with methods that directly measure keratinocyte motility in response to extracellular matrix and growth factors (16-18). In this study, we examined the effects of hypoxia on human keratinocyte migration over connective tissue components.

\section{Methods}

Keratinocyte cultures. Human keratinocytes obtained from surgical skin specimens (two adults, ages 34 and 46) and neonatal foreskins (10 different donors) were cultured in low calcium, serum-free medium (SFM; GIBCO BRL, Gaithersburg, MD) or Keratinocyte Growth Medium (KGM ${ }^{1}$ Clonetics, San Diego, CA) as described by Boyce and Ham (19) and modified by O'Keefe and Chiu (20).

Oxygen systems. The standard oxygen level was defined as the $\mathrm{pO}_{2}$ which exists in a standard, conventional, humidified tissue culture incubator at $37^{\circ} \mathrm{C}(20 \%)$. The low $(0.2-2 \%)$ and tissue normoxia $(9 \%)$ oxygen systems were established in a humidified environmental chamber set at $37^{\circ} \mathrm{C}$ (Coy Laboratory Products, Ann Arbor, Michigan). This incubator uses an oxygen analyzer to monitor and maintain the selected chamber oxygen concentration. This oxygen concentration was maintained with a calibrated gas mixture of $95 \%$ nitrogen and $5 \%$ carbon dioxide.

1. Abbreviation used in this paper: KGM, Keratinocyte Growth Medium. 
Antibodies and matrices. Native rat type I collagen was purchased from Calbiochem Corp. (La Jolla, CA) and human type IV collagen from Sigma Chemical Co. (St. Louis, MO). Human plasma fibronectin was obtained from GIBCO BRL. Laminin-1 was prepared from the Engelbreth-Holm-Swarm tumor as described previously (21). Laminin-5 was purified according to Marinkovich et al., as described previously (22). Mouse mAbs against $\alpha 2$ (P1E6), $\alpha 3$ (P1B5), $\alpha 5$ (P1D6), $\beta 1$ (P4C10), and $\beta 4$ (3E1) integrin subunits were obtained from GIBCO BRL (23-26). A mouse $\mathrm{mAb}$ against the EGF receptor (clone 74) was obtained from GIBCO BRL. GB3 antibody, recognizing the $\gamma 2$ chain of laminin-5, was purchased from Accurate Chemical and Science Corp. (Westbury, NY) (27).

Keratinocyte migration assays. Keratinocyte migration was assessed by the method of Albrecht-Buehler (28), as modified by Woodley et al. (17). Briefly, colloidal gold salts were immobilized on coverslips and covered with extracellular matrix components such as type I collagen, type IV collagen, laminin, or fibronectin. Second to fourth passage keratinocyte cultures were suspended and plated on the coverslips and allowed to migrate for $16 \mathrm{~h}$. The cells were fixed in $0.1 \%$ formaldehyde in PBS and examined under dark field optics with a video camera attached to a computer equipped with a frame grabber. The computer analyzes 15 nonoverlapping fields in each experimental condition with NIH Image 1.6 and determines the percentage area of each field consumed by cell migration tracks, a socalled Migration Index. The lengths of individual tracks were also measured. Confirmation of a difference in migration as statistically significant requires rejection of the null hypothesis of no difference between mean migration indices obtained from replicate sets at the $P=0.05$ level with a Student's $t$ test (29). All migration assays were performed at $0.2,2,9$ (tissue normoxia), and 20\% oxygen (incubator normoxia), respectively.

A second migration assay, the so-called scratch assay was performed according to Cha et al., as described previously (30). Keratinocytes $\left(40,000 / \mathrm{cm}^{2}\right)$ were plated in tissue culture dishes, and after $24 \mathrm{~h}$ of incubation, the confluent monolayer of cells was scratched in a standardized manner with a plastic apparatus to create a cell-free zone in each well, $2 \mathrm{~mm}$ in width. The medium was aspirated and replaced with keratinocyte medium with or without type I collagen (15 $\mu \mathrm{g} / \mathrm{ml})$ diluted in keratinocyte medium. The cells were then incubated under normoxic and hypoxic conditions for an additional $16 \mathrm{~h}$. In vitro wound closure was monitored by the repopulation of the cleared area with cells over time. The amount of migration was quantitated by computer-assisted image analysis using NIH Image 1.6. The residual gap between the migrating keratinocytes was measured and expressed as a percentage of the initial total scratch area. Each experiment was repeated three times.

Under hypoxic conditions, the medium $\mathrm{pH}$ drops to 7.1 over an $18 \mathrm{~h}$ period (personal observation). In sterile wounds the $\mathrm{pH}$ is 7.0 7.2 (15). The $\mathrm{pH}$ of SFM under normoxic conditions is 7.5. To assess the effect of lowering the $\mathrm{pH}$ of keratinocyte medium on keratinocyte motility, neonatal human keratinocytes in low calcium serum-free KGM were plated at a density of 1,000 cells $/ \mathrm{cm}^{2}$ onto a matrix of type I collagen at a concentration of $15 \mu \mathrm{g} / \mathrm{ml}$. The cells were allowed to attach for $2 \mathrm{~h}$ at $37^{\circ} \mathrm{C}$, the medium aspirated and replaced with medium that had been $\mathrm{pH}$ adjusted from 7.5 by the step-wise addition of either $\mathrm{HCl}$ or lactic acid while the oxygen tension was held at $9 \%$ (tissue normoxia). The cells were allowed to migrate overnight, fixed with $0.1 \%$ formaldehyde and the migration index was then calculated. To circumvent the minor change in $\mathrm{pH}$ caused by hypoxia, keratinocytes were incubated in the colloidal gold migration assay under hypoxic conditions in keratinocyte medium buffered with $10 \mathrm{mM}$ Hepes to equilibrate the $\mathrm{pH}$ at a constant level of 7.5, and the migration assay was allowed to continue, as described above.

Protein synthesis. To compare total protein synthesis by keratinocytes under normoxic and hypoxic conditions, subconfluent numbers of cells were plated onto type I collagen $(15 \mu \mathrm{g} / \mathrm{ml})$ or no matrix and incubated under normoxic $(20 \%)$ or hypoxic $(2 \%)$ conditions for $16 \mathrm{~h}$, in methionine-free KGM (Clonetics) in the presence of [ $\left.{ }^{\mathrm{S}} 35\right] \mathrm{me}-$ thionine (ICN Biomedicals, Inc., Irvine, CA) $-10 \mu \mathrm{Ci} / 1.5 \mathrm{ml}$. Two different labeling schedules were used. The label was added immediately after keratinocyte attachment and incubated for $16 \mathrm{~h}$, or the cells were incubated in normoxic or hypoxic conditions for $12 \mathrm{~h}$ and the label added $4 \mathrm{~h}$ before collection. In both methods, the conditioned medium was collected after a $16 \mathrm{~h}$ total incubation period. The cell layers and associated matrix were extracted. Aliquots $(50 \mu \mathrm{l})$ of conditioned medium were precipitated in $10 \% \mathrm{TCA}$ at $4^{\circ} \mathrm{C}$ for 10 minutes. The pellets were washed with $5 \%$ TCA $(\times 3)$ at $4^{\circ} \mathrm{C}$ to remove any nonprotein associated counts and dissolved in $1 \mathrm{~N}$ sodium hydroxide $(100 \mu \mathrm{l})$ before addition of scintillation fluid (Sigma Chemical Co.). After sonication and centrifugation, the supernatant was collected. Aliquots were added to the scintillation cocktail and counted on a Beckman Scintillation Counter. Keratinocytes were also plated at a density of 20,000 cells per $\mathrm{cm}^{2}$ under normoxic and hypoxic conditions for $16 \mathrm{~h}$. The cells were extracted in $0.8 \mathrm{ml}$ of $0.125 \mathrm{M}$ Tris $\mathrm{HCl}, \mathrm{pH} 6.8,2 \%$ SDS (sample buffer without bromophenol blue dye) and the protein concentration determined by the method of Lowry et al. (31).

Western immunoblots for ezrin, radixin, and moesin. Keratinocytes driven to migrate by type I collagen were subjected to normoxic and hypoxic conditions and evaluated for the relative expression of the lamellipodia associated proteins, ezrin, radixin, and moesin (32). Briefly, keratinocytes were plated sparsely $\left(12,500 / \mathrm{cm}^{2}\right)$ on type I collagen, and cultured for $18 \mathrm{~h}$ under normoxic or hypoxic conditions. The cell layers were washed in cold PBS three times and then $0.8 \mathrm{ml}$ of $0.125 \mathrm{M}$ Tris $\mathrm{HCl}, \mathrm{pH} 6.8,2 \%$ SDS (sample buffer) or $0.8 \mathrm{ml} 10 \mathrm{mM}$ Tris, $\mathrm{pH} 7.5,140 \mathrm{mM} \mathrm{NaCl}, 1 \%$ Triton $\mathrm{X}-100$ was added to the cell layers. The cell layer was scraped with a plastic policeman and the buffer collected. The extracts were vortexed for $1 \mathrm{~min}$, sonicated for $30 \mathrm{~s}$, and centrifuged at $100,000 \mathrm{~g}$ for $15 \mathrm{~min}$. The soluble supernatant was collected and the protein concentration determined according to Lowry et al. (31). After the protein determinations, bromophenol blue dye, $5 \mathrm{mM}$ DTT, $1 \mathrm{mM}$ EDTA, and $1 \mathrm{mM}$ PMSF were added to the sample buffer extracts. The Triton X-100 extracts were mixed with equal amounts of $2 \times$ sample buffer containing bromophenol blue dye, $10 \mathrm{mM}$ DTT, $2 \mathrm{mM}$ EDTA, and $2 \mathrm{mM}$ PMSF. The samples were boiled and equal amounts of protein were subjected to SDSPAGE and Western immunoblotting according to Towbin et al. (33). Identical nitrocellulose strips were incubated with polyclonal antibodies to ezrin (pAs 90.3, dilution 1:1,000), radixin (pAs 92.4, dilution 1:1,000), and moesin (pAs 90.7, dilution 1:300) and a mAb to actin (1: 10,000) for $2 \mathrm{~h}(34)$. The nitrocellulose strips were then incubated with secondary peroxidase conjugated goat anti-rabbit IgG at a dilution of 1:2,000 or peroxidase conjugated goat anti-mouse $\mathrm{IgG}$ at a dilution of 1:1,000 (Organon Teknika-Cappel, Durham, NC) for $1 \mathrm{~h}$ and the membrane was developed using ECL (Amersham Corp., Arlington Heights, IL) or a four CN Membrane Peroxidase Substrate System (Kirkegaarde \& Perry Laboratories, Inc., Gaithersburg, MD). This experiment was repeated four times with four different keratinocyte donors (two adult, two neonatal).

Immunofluorescence. Keratinocytes were plated in TissueTek chamber slides (Nunc, Inc., Naperville, IL), on type I collagen at a density of 12,500 cells $/ \mathrm{cm}^{2}$ and cultured under normoxic and hypoxic conditions for $18 \mathrm{~h}$. The keratinocytes were immersed in periodatelysine-paraformaldehyde fixative for $10 \mathrm{~min}$ at room temperature (35). The cells were washed several times with PBS to remove fixative, and then permeabilized and blocked by incubating in PBS with $3 \%$ BSA, $1 \%$ saponin, and $0.05 \% \mathrm{Na}$ Azide for $10 \mathrm{~min}$ at room temperature. The cells were incubated with ezrin antibody, pAs 90.3 at a dilution of 1:200 in a humidified chamber for $2 \mathrm{~h}$, then washed three times with PBS, $1 \%$ saponin, counterstained with a FITC-conjugated goat antibody to rabbit IgG (1:100 dilution) for $1 \mathrm{~h}$ (Organon Teknika-Cappel) and washed. The cells were then examined and photographed with a Zeiss epiluminating immunofluorescence microscope at a magnification of 330 .

Western immunoblot for laminin-5 ( $\beta 3$ and $\gamma 2$ chains) and fibronectin. Normal human keratinocytes were plated on plastic cul- 
ture dishes at a density of 17,500 cells $/ \mathrm{cm}^{2}$. The cells were incubated under normoxic and hypoxic conditions for $18 \mathrm{~h}$ to allow adequate time for laminin-5 deposition. The matrix was extracted by serial extraction with Triton X-100 for $5 \mathrm{~min}, 2 \mathrm{M}$ urea and $0.1 \mathrm{M} \mathrm{NaCl}$ for 10 $\mathrm{min}$, and $8 \mathrm{M}$ urea for $10 \mathrm{~min}$, as described (36). The remaining substratum was extracted in sample buffer $(0.125 \mathrm{M}$ Tris $\mathrm{HCl}, \mathrm{pH} 6.8$, $2 \%$ SDS). All solutions contained $1 \mathrm{mM}$ PMSF and $2 \mathrm{mM} \mathrm{NEM}$ ( $N$-ethylmaleimide). The samples were separated by SDS-PAGE on a 5\% acrylamide slab gel. The separated proteins were electrophoretically blotted to a nitrocellulose membrane, according to Towbin et al. (33) and labeled with polyclonal antibodies to the $\beta 3$ chain and $\gamma 2$ chain of laminin-5 at a dilution of 1:1,000 (generously supplied by Dr. Warren Hoeffler, Stanford University, Stanford, CA). Purified laminin-5 was used as a positive control. The nitrocellulose membranes were then incubated with secondary peroxidase conjugated goat antirabbit $\mathrm{IgG}$ at a dilution of 1:2,000 (as above) for $1 \mathrm{~h}$ and the membrane was developed using ECL. The experiment was repeated using three neonatal and two adult donors. A duplicate control blot with fibronectin as a positive control was labeled with a polyclonal IgG antibody to human fibronectin at a dilution of 1:1,000 (Organon TeknikaCappel). The nitrocellulose membranes were then incubated with a secondary peroxidase conjugated rabbit anti-goat IgG at a dilution of 1:2,000 (Bio-Rad Laboratories, Richmond, CA) and developed using ECL (vide supra).

Laminin-5 immunofluorescence. Keratinocytes were cultured in TissueTek chamber slides (Nunc, Inc.) under normoxic and hypoxic conditions for $18 \mathrm{~h}$. The keratinocyte monolayers were extracted by serial extraction as described above and the remaining deposited extracellular matrix was stained with GB3 antibody for laminin-5. The cells were fixed with ice-cold methanol, washed several times with PBS to remove fixative, and then permeabilized and blocked by incubating for $10 \mathrm{~min}$ at room temperature in PBS with 3\% BSA, 1\% saponin, and $0.05 \%$ Na Azide. The cells were incubated with GB3 antibody at a dilution of 1:10 in a humidified chamber for $1 \mathrm{~h}$, then washed three times with PBS with $1 \%$ saponin, counterstained with FITC-conjugated goat antibody to mouse IgG (1:25 dilution) for $1 \mathrm{~h}$ (Kirkegaarde \& Perry Laboratories, Inc.), washed and the matrix deposited on the slides examined and photographed with a Zeiss immunofluorescence microscope at a magnification of 100.

Fluorescent-activated cell sorting $\left(F A C S^{\circledR}\right)$. To determine the profile of cell-surface integrins on keratinocytes migrating on matrix and subjected to normoxic and hypoxic conditions, FACS ${ }^{\circledR}$ analysis was performed according to Chen et al. (29) with antibodies to $\alpha 2, \alpha 3, \alpha 5$, $\beta 1, \beta 4$ integrin subunits or the EGF receptor. All primary antibodies were used at a dilution of 1:100. A FITC conjugated anti-mouse secondary antibody purchased from Jackson ImmunoResearch Labs (Bar Harbor, ME) was used as the secondary antibody at a dilution of 1:200.

Zymography and immunoblot for $92 \mathrm{kD}$ collagenase. Normal human keratinocytes were plated on plastic and type I collagen at a density of $17,500 \mathrm{cells} / \mathrm{cm}^{2}$. The cells were incubated under normoxic and hypoxic conditions for $18 \mathrm{~h}$. Gelatinolytic proteinases were assayed by gelatin-substrate enzymography (37). Type I collagen heated at $56^{\circ} \mathrm{C}$ for $20 \mathrm{~min}$ was incorporated into a $10 \%$ acrylamide gel. Aliquots of medium $(15 \mu \mathrm{l})$ were prepared for electrophoresis without heating or reduction, after concentration $\times 5$ with Centricon- 10 . After SDSPAGE, SDS was removed from the gels by $2.5 \%$ (vol/vol) Triton $\mathrm{X}-100$ washes $(2 \times 20 \mathrm{~min})$, and the gels incubated in assay buffer (15 mM Tris-Cl, pH 7.4, $5 \mathrm{mM} \mathrm{CaCl}{ }_{2}$ with $1 \mathrm{mM}$ PMSF and $2 \mathrm{mM}$ $\mathrm{NEM})$ at $37^{\circ} \mathrm{C}$ for $24 \mathrm{~h}$. The reaction was stopped by staining the gels with Coomassie Brilliant Blue. Gelatinolytic activity was detected as clear bands against the aqua-blue stained gelatin background.

In order to determine the expression of the 92-kD type IV collagenase by another independent method, the samples were also subjected to SDS-PAGE on $10 \%$ acrylamide gels, the protein electrophoretically blotted to nitrocellulose membranes and labeled with a polyclonal peptide antibody to the $92-\mathrm{kD}$ type IV collagenase (Triple Point Biologics, Forest Grove, OR) at a dilution of 1:1000 overnight at $4^{\circ} \mathrm{C}$. The nitrocellulose membranes were then incubated with secondary peroxidase-conjugated goat anti-rabbit $\mathrm{IgG}$ at a dilution of 1:2,000 for $1 \mathrm{~h}$ and developed using ECL.

Densitometry. To quantitate the intensity of individual bands, the optical density and area were measured by scanning the film with a Bio-Rad BLS-670 densitometer (Bio-Rad Laboratories).

\section{Results}

Effect of hypoxia on keratinocyte migration. In order to examine the effect of hypoxia on keratinocyte migration, we performed two distinct keratinocyte migration assays. As shown in Fig. 1, $A$ and $B$, human keratinocytes juxtaposed to an extracellular matrix of type I collagen exhibit increased cellular migration under hypoxic conditions compared with normoxic conditions (compare $1 A$ [normoxic] with $1 B$ [hypoxic]). As shown in Fig. 2, the computer-generated Migration Indices increased 1.5-2.0-fold under hypoxic conditions versus normoxic conditions on type I collagen, type IV collagen and fibronectin using neonatal donor keratinocytes. A 1.5-2.0-fold increase in the Migration Indices under hypoxic conditions was also demonstrated using adult donor keratinocytes (data not shown). This hypoxia-driven enhanced motility was not observed when the cells were opposed to tissue culture plastic, albumin or laminin. Comparable Migration Indices were obtained under tissue normoxia $\left(9 \% \mathrm{O}_{2}\right)$ and incubator normoxia $\left(20 \% \mathrm{O}_{2}\right)$ and also under both hypoxic conditions $\left(2 \%\right.$ and $\left.0.2 \% \mathrm{O}_{2}\right)$ (data not shown).
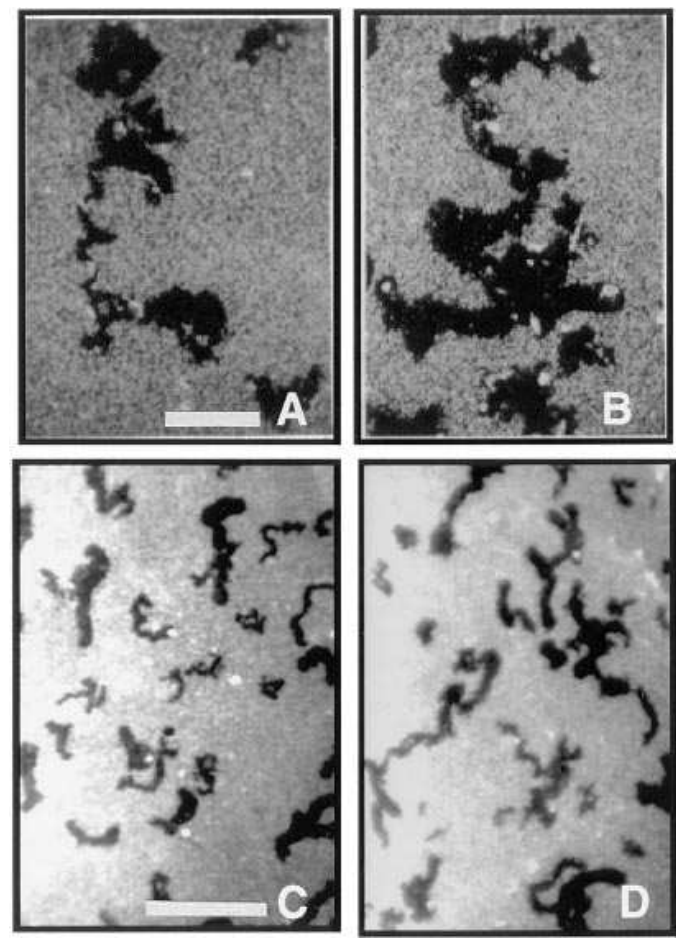

Figure 1. The effect of hypoxia on keratinocyte migration on extracellular matrix. ( $A$ and $B$ ) Migration of human keratinocytes on collagen I after $16 \mathrm{~h}$ of culture under normoxic conditions $(A)$ and hypoxic conditions $(B)$. Migration tracks appear black under dark field optics. Keratinocytes exhibit increased motility under hypoxic conditions. $(C$ and $D)$ Low power view of the migration tracks under normoxic $(C)$ and hypoxic $(D)$ conditions. (A) Bar, $100 \mu \mathrm{m}$; $(C)$ bar, $300 \mu \mathrm{m}$. 


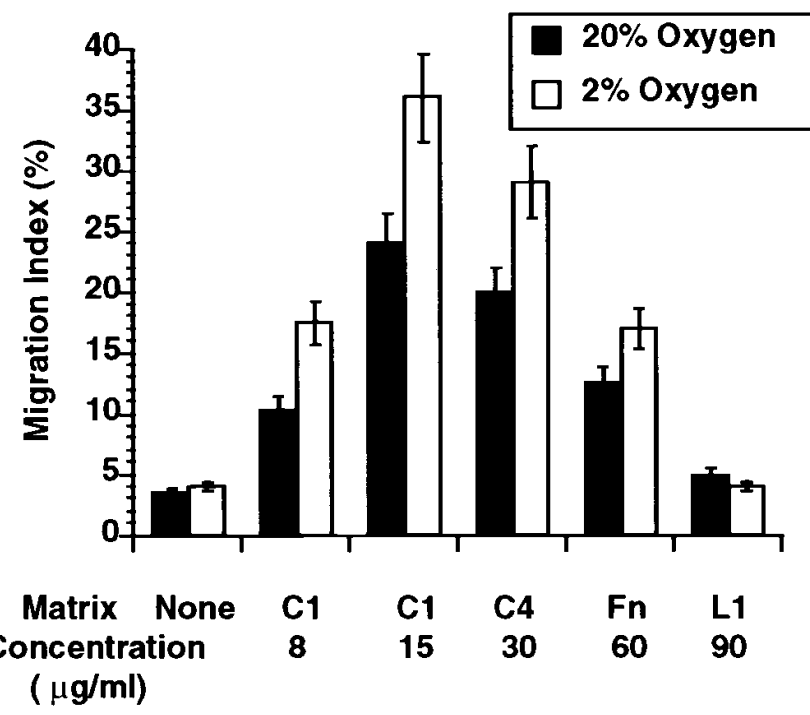

Figure 2. Hypoxia increases keratinocyte motility. Hypoxic conditions increase keratinocyte motility $50-100 \%$ over normoxic conditions on optimal levels of collagen I ( 4 and $15 \mu \mathrm{g} / \mathrm{ml})$, collagen IV $(30 \mu \mathrm{g} / \mathrm{ml})$ and fibronectin $(60 \mu \mathrm{g} / \mathrm{ml})$ using neonatal donors. These findings are representative of four different experiments using four donors. No statistically significant difference was noted on laminin or no matrix.

The motile keratinocytes also form longer tracks under hypoxic conditions as demonstrated in the lower power view of the dish surface in Fig. 1, $C$ and $D$, normoxic versus hypoxic, respectively. As shown in Table I, the mean track length increased by $\sim 40 \%$ under hypoxic conditions in two neonatal donors and one adult donor when compared with identical cells migrating under normoxic conditions for exactly the same time.

In the in vitro wound assay, keratinocytes were plated densely in tissue culture wells and after $24 \mathrm{~h}$ a standardized scratch was made through the confluent monolayer as described previously (30). The keratinocytes from the cut edge of the scratch were then allowed to migrate for $12 \mathrm{~h}$ under normoxic or hypoxic conditions on type I collagen $(15 \mu \mathrm{g} / \mathrm{ml})$ or

Table I. The Effect of Hypoxia on Migrating Human Keratinocyte Track Length

\begin{tabular}{lcr}
\hline & Normoxia $\left(20 \% \mathrm{O}_{2}\right)$ & Hypoxia $\left(2 \% \mathrm{O}_{2}\right)$ \\
\hline Donor 1 & $163.8 \pm 21.2$ & $221.1 \pm 19.3$ \\
Donor 2 & $158.8 \pm 19.1$ & $234.2 \pm 24.5$ \\
Donor 3 & $149.9 \pm 16.4$ & $220.3 \pm 20.9$
\end{tabular}

Neonatal human keratinocytes in low calcium serum-free SFM were plated at a density of 1,000 cells $/ \mathrm{cm}^{2}$ onto a matrix of collagen I at a concentration of $15 \mu \mathrm{g} / \mathrm{ml}$. The cells were allowed to attach for $2 \mathrm{~h}$ at $37^{\circ} \mathrm{C}$ and then incubated under normoxic and hypoxic conditions. The cells were allowed to migrate overnight, fixed with $0.1 \%$ formaldehyde and the length of individual keratinocyte tracks was calculated by computeraided image analysis. As shown above, the length of the migration tracks is clearly increased under hypoxic conditions. Values are mean \pm SEM of 10 tracks of three donors in micrometers. no matrix, and photographed. The residual scratch area between the inwardly migrating keratinocytes from the edges of the scratch was measured as described in Methods. As shown in Fig. 3, the keratinocytes migrated inwardly and covered a greater area of the scratch under hypoxic conditions (Fig. 3, $B$ and $D$ ) compared with normoxic conditions (Fig. 3, $A$ and $C$ ). Further, the increased keratinocyte motility under hypoxic conditions relative to normoxic conditions was observed when the cells were apposed to both type I collagen and tissue culture plastic. As shown in Fig. $3 E$, keratinocytes on plastic under normoxic conditions $(A)$ migrated to fill $44 \pm 2 \%$ of the scratch area. The filled area increased to $62 \pm 4 \%$ under hypoxic conditions $(B)$. Keratinocytes migrating on type I collagen under normoxic conditions filled $60 \pm 3 \%$ of the scratch area $(C)$, while the filled area increased to $82 \pm 5 \%$ under hypoxic conditions $(D)$.

Effect of pH on keratinocyte motility. Because hypoxia is associated with a lower $\mathrm{pH}$ of 7.1 in the culture medium (our observation), we sought to determine if a lower medium $\mathrm{pH}$ itself could influence keratinocyte motility as a variable indepen-
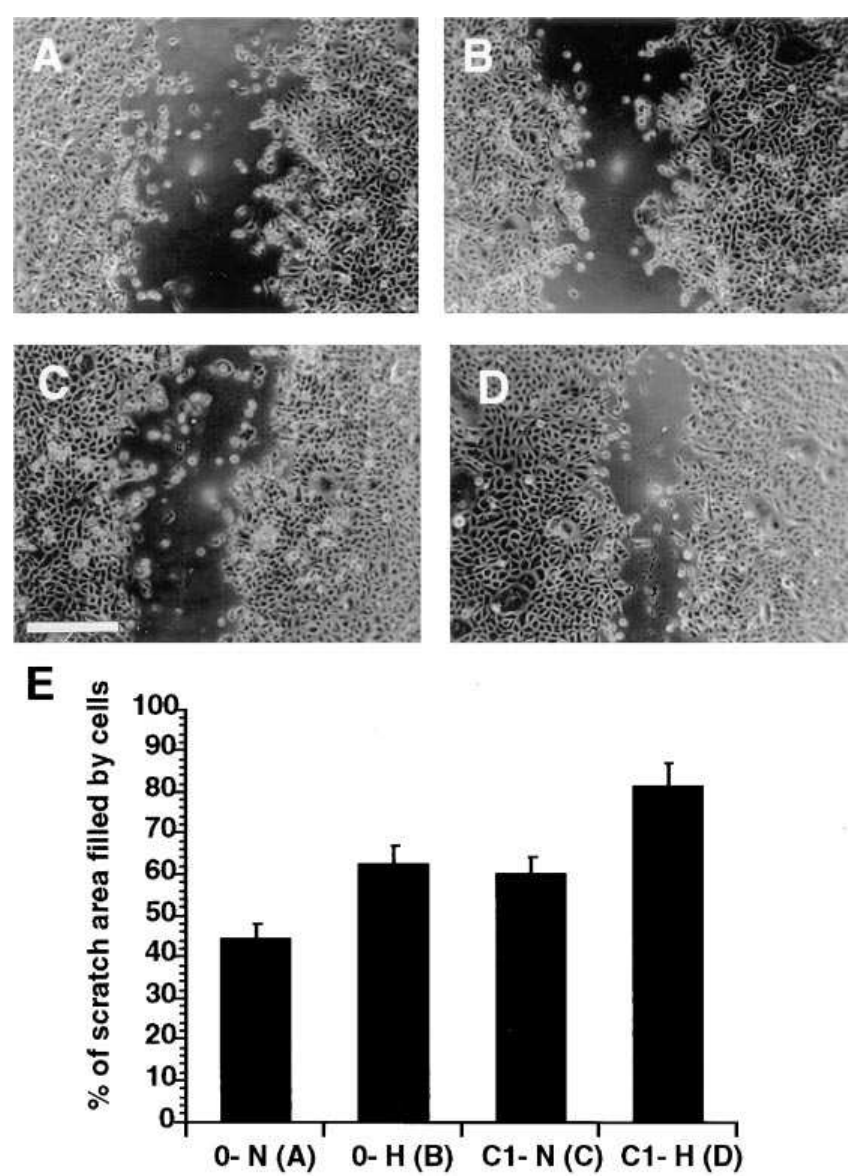

Figure 3. Effect of hypoxia on in vitro wound closure with and without collagen I. An in vitro wound was introduced in confluent cultures of normal human keratinocytes, as described in Methods. The cells were incubated without ( $A$ and $B$ ) or with collagen $\mathrm{I} 15 \mu \mathrm{g} / \mathrm{ml}$ $(C$ and $D)$ and incubated under normoxic $(A$ and $C)$ or hypoxic conditions $(B$ and $D)$. After $12 \mathrm{~h}$, the cells were photographed under phase-contrast microscopy. Bar, $200 \mu \mathrm{m}$. The percent of the scratch area was calculated by image analysis and expressed as the mean \pm SEM of three observations $(E)$. 
dent from hypoxia. To determine if the enhanced motility observed under hypoxic conditions could be explained by altered $\mathrm{pH}$, keratinocyte migration assays under normoxic conditions were performed with and without the presence of exogenously added hydrochloric acid and/or lactic acid which induced corresponding decreases in $\mathrm{pH}$. Human keratinocyte viability and proliferation are not affected by a medium $\mathrm{pH}$ as low as 5.4 (38). Progressively lower $\mathrm{pH}$ conditions are associated with decreased keratinocyte migration on type I collagen (Table II). A pH of 7.1 does not affect keratinocyte motility on extracellular matrix. However, a decrease in medium pH to 6.1 significantly inhibits keratinocyte motility (Table II). To circumvent the minor change in $\mathrm{pH}$ caused by hypoxia, keratinocytes were incubated under hypoxic conditions, but the medium was buffered with $10 \mathrm{mM}$ Hepes to maintain the $\mathrm{pH}$ at 7.5. As shown in Table II, the increase in keratinocyte migration under hypoxic conditions was still apparent.

Hypoxia does not affect protein synthesis. Total protein synthesis and secretion by the keratinocyte cultures was not significantly altered under the conditions of the assay by hypoxia compared with normoxia. Regardless of the two schedules of adding $\left[{ }^{35} \mathrm{~S}\right]$ methionine to the cultures, the TCA precipitable counts of incorporated methionine into newly synthesized proteins were essentially equal under both hypoxic and normoxic conditions in neonatal and adult donors (data not shown). The protein concentration of keratinocytes incubated under normoxic and hypoxic conditions was also assayed by the method of Lowry et al. (31), and no change in total cellular protein concentration was found (data not shown). These data are consistent with those of Herrick et al. who demonstrated recently that dermal fibroblast total protein synthesis is similar under normoxic and hypoxic conditions (39).

Hypoxia-induced redistribution of ezrin, radixin, and moesin. Ezrin, radixin, and moesin (ERM proteins) are constitutive proteins of epithelial cells that play a role in the formation of lamellipodia, plasma membrane extrusions present in motile

Table II. The Effect of Altering Environment pH on Keratinocyte Migration

\begin{tabular}{|c|c|c|c|c|}
\hline \multirow{2}{*}{$\begin{array}{l}\mathrm{pO}_{2} \\
\text { Additive } \\
\mathrm{pH}\end{array}$} & \multicolumn{2}{|c|}{$9 \% \mathrm{O}_{2}$} & \multirow{2}{*}{$\begin{array}{c}9 \% \mathrm{O}_{2} \\
\text { Hepes } 10 \mathrm{mM} \\
\text { MI }\end{array}$} & \multirow{2}{*}{$\begin{array}{c}2 \% \mathrm{O}_{2} \\
\text { Hepes } 10 \mathrm{mM} \\
\text { MI }\end{array}$} \\
\hline & $\begin{array}{l}\mathrm{HCl} \\
\mathrm{MI}\end{array}$ & $\begin{array}{c}\text { Lactic acid } \\
\text { MI }\end{array}$ & & \\
\hline 7.5 & $28 \pm 4 \%$ & $28 \pm 5 \%$ & $29 \pm 4.5 \%$ & $37 \pm 4 \%$ \\
\hline 7.1 & $28 \pm 4 \%$ & $28 \pm 3 \%$ & & \\
\hline 6.1 & $18 \pm 3 \%$ & $17 \pm 4 \%$ & & \\
\hline
\end{tabular}

Neonatal human keratinocytes in low calcium serum-free SFM were plated at a density of 1,000 cells $/ \mathrm{cm}^{2}$ onto a matrix of collagen $\mathrm{I}$ at a concentration of $15 \mu \mathrm{g} / \mathrm{ml}$. The cells were allowed to attach for $2 \mathrm{~h}$ at $37^{\circ} \mathrm{C}$, the medium aspirated and replaced with medium that had been $\mathrm{pH}$ adjusted from 7.1 by the step-wise addition of $\mathrm{HCl}$ and lactic acid while the oxygen tension was held at $9 \%$ (tissue normoxia). The cells were allowed to migrate overnight, fixed with $0.1 \%$ formaldehyde and the percentage of the total field area consumed by migration tracks was calculated (the Migration Index). As shown above, as the $\mathrm{pH}$ decreases, the migration index decreases on collagen I. To circumvent the minor change in $\mathrm{pH}$ caused by hypoxia, keratinocytes were incubated under hypoxic conditions, but the medium was buffered with $10 \mathrm{mM}$ Hepes. The increase in migration under hypoxic conditions was still apparent. Values are mean \pm SEM of 15 different field calculations in three donors.

\section{Donor 1 Donor 2 Donor 3 Donor 4}

$$
\begin{aligned}
& 11 / 111 \\
& \begin{array}{lllllllll} 
& \mathrm{N} & \mathrm{H} & \mathrm{N} & \mathrm{H} & \mathrm{N} & \mathrm{H} & \mathrm{N} & \mathrm{H}
\end{array}
\end{aligned}
$$

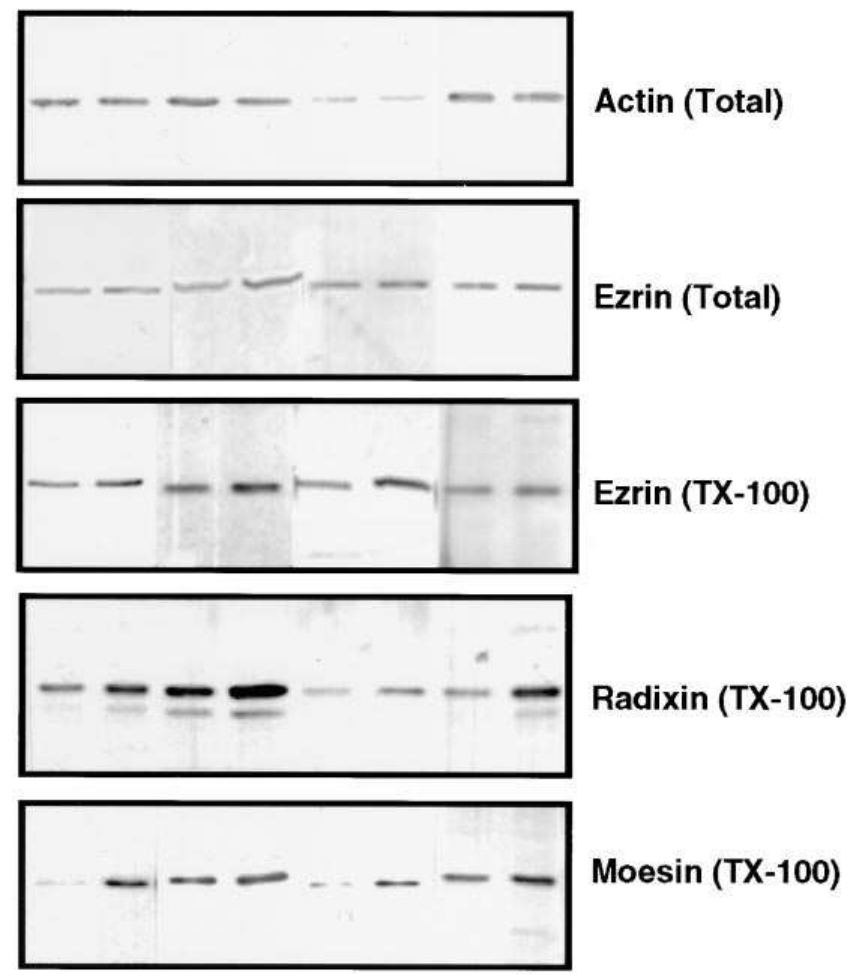

Figure 4. Western blot demonstrating expression of ezrin and actin (total protein), ezrin, radixin, and moesin (plasma-membrane associated or Triton X-100 soluble) under normoxic and hypoxic conditions. Ezrin $\left(M_{r}=85,000\right)$, radixin $\left(M_{r}=81,000\right)$, and moesin $\left(M_{r}=\right.$ $78,000)$ are lamellipodia-associated proteins. Keratinocytes plated on collagen I were incubated under normoxic and hypoxic conditions for 18 h. Donor keratinocytes ( 1 and 3, neonatal; 2 and 4, adult) were extracted in sample buffer and equal amounts of protein were subjected to SDS-PAGE. A representative experiment using each donor is shown.

cells (32). Because we observed that hypoxia induced enhanced keratinocyte motility, we postulated that the hypoxiadriven increased motility might be associated with a redistribution or increased expression of ERM proteins and increased lamellipodia formation. Total protein and Triton X-100 soluble protein extracts of keratinocyte cultures under normoxic or hypoxic conditions for $24 \mathrm{~h}$ were prepared and the expression of the lamellipodia-associated proteins ezrin, radixin, and moesin compared by Western immunoblot analysis. Enhanced expression of the plasma membrane associated ezrin, radixin, and moesin (Triton X-100 soluble) under hypoxic conditions compared with normoxic cultures was reproducibly demonstrated in four different experiments using different donor keratinocytes (Fig. 4). Representative experiments are shown in Fig. 4 (Ezrin TX-100, Radixin TX-100, and Moesin TX-100). By relative densitometry quantitation, the upward modulation by hypoxia was at least $100 \%$ for radixin and moesin and $\sim 75 \%$ for ezrin (Fig. 5). Total ezrin, radixin, and moesin expression 


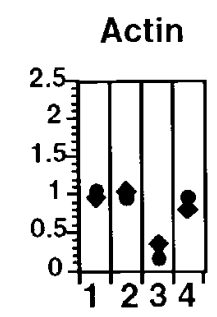

\section{Ezrin-Tx}

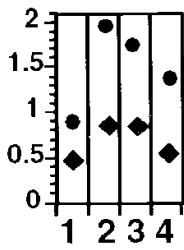

\section{- Hypoxia}

- Normoxia

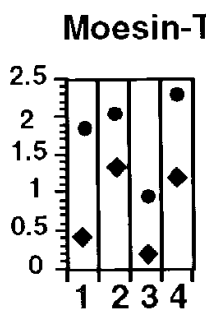

\section{Ezrin}

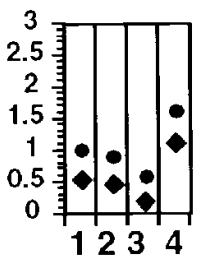

Figure 5. Densitometry values of bands shown in Fig. 4. To quantitate the intensity of individual bands, the optical density and area of each band were measured by scanning the film with a Bio-Rad BLS670 densitometer. Each value represents the $\mathrm{OD} \times$ area $\left(\mathrm{mm}^{2}\right)$ of an individual band.

were also upregulated under hypoxic conditions in two neonatal and two adult donors, however, this upregulation was not as evident as the upregulation in the plasma membrane-associated fraction (data not shown for moesin and radixin, Fig. 4: ezrin labeled Ezrin Total). By relative densitometry quantitation, the upward modulation by hypoxia was $50 \%$ or greater of the normoxic condition in four identical experiments (see Fig. 5, Ezrin). We observed negligible change in the total actin expression under normoxic or hypoxic conditions (Figs. 4 and 5, Actin Total and Actin, respectively).

To examine more directly the morphology of keratinocyte lamellipodia under normoxic and hypoxic conditions, we immunolabeled keratinocytes migrating on type I collagen with a monospecific antibody to ezrin under varying oxygen tensions and then examined and photographed the cells. Representative microscopic fields are shown in Fig. 6 of keratinocytes migrating on type I collagen under normoxic and hypoxic conditions stained with ezrin antibody. As noted in the figure, the apron and the protruding lamellipodia become more elongated and more prominent under hypoxic conditions when compared with normoxic conditions (compare Fig. 6, $A$ and $B)$. This direct observation of enhanced lamellipodia formation being induced by hypoxia is concordant with the increased expression of the ERM proteins and redistribution of these proteins to the plasma membrane under hypoxic conditions.

Effect of hypoxia on laminin-5 secretion by keratinocytes. Laminin-5 is an important matrix attachment ligand for cultured keratinocytes and has been shown to inhibit keratinocyte motility $(40,41)$. We hypothesized that hypoxia might decrease keratinocyte secretion of laminin- 5 and make the cell less firmly attached to the substratum. This process of less substratum anchorage would allow the cells to exhibit enhanced motility. To examine this hypothesis, we assessed the level of secreted laminin-5 in keratinocyte cultures under normoxic and hypoxic conditions. Equal amounts of protein, extracted from cells under normoxic and hypoxic conditions and sub-

jected to Western analysis, were probed with polyclonal antibodies to the $\beta 3$ and $\gamma 2$ chains of laminin-5, a major adhesion molecule for human keratinocytes. As demonstrated in Fig 7, $A$ and $B$ (lanes 4 and 5), keratinocyte secretion of laminin-5 was decreased under hypoxic conditions compared with normoxic conditions. The intracellular laminin-5 (lanes 2 and 3) was not affected by hypoxia. Shown in Fig. $7 C$ is a duplicate blot probed with a polyclonal antibody to fibronectin. One can see that there is no change in the intracellular (lanes 2 and 3) or secreted (lanes 4 and 5) fibronectin expression under hypoxic (lanes 3 and 5) conditions compared with normoxic conditions (lanes 2 and 4). Shown in Fig. $7 D$ are representive Western blots and densitometry values of the expression of the $\gamma 2$ chain of laminin-5 (155 kD) under normoxic and hypoxic conditions of three donors (two adult and one neonatal), confirming the selective decrease in the secretion of laminin-5 under hypoxic conditions.

In addition to Western blot analyses, we wished to directly assess the expression of secreted laminin- 5 by migrating human keratinocytes under normoxic and hypoxic conditions by immunolabeling the cells with a monospecific antibody to laminin-5. As shown in Fig. $8 \mathrm{~A}$, keratinocytes secrete copious
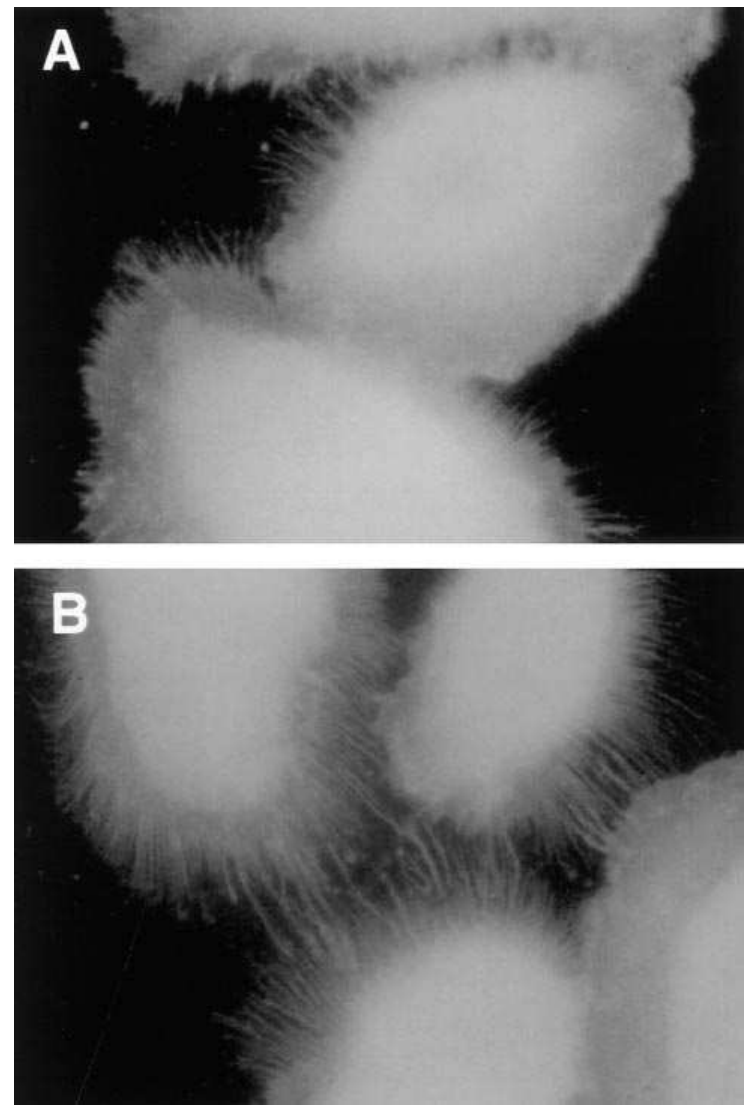

Figure 6. Immunofluorescence staining of ezrin under normoxic and hypoxic conditions. Human neonatal keratinocytes were plated on type I collagen, $15 \mu \mathrm{g} / \mathrm{ml}$, and incubated under normoxic $(A)$ and hypoxic $(B)$ conditions. The keratinocytes were washed with $\mathrm{PBS}$, fixed and stained with a polyclonal antibody to ezrin and a FITC-conjugated secondary antibody. The cells were photographed with a Zeiss immunofluorescence microscope. $\times 320$. 

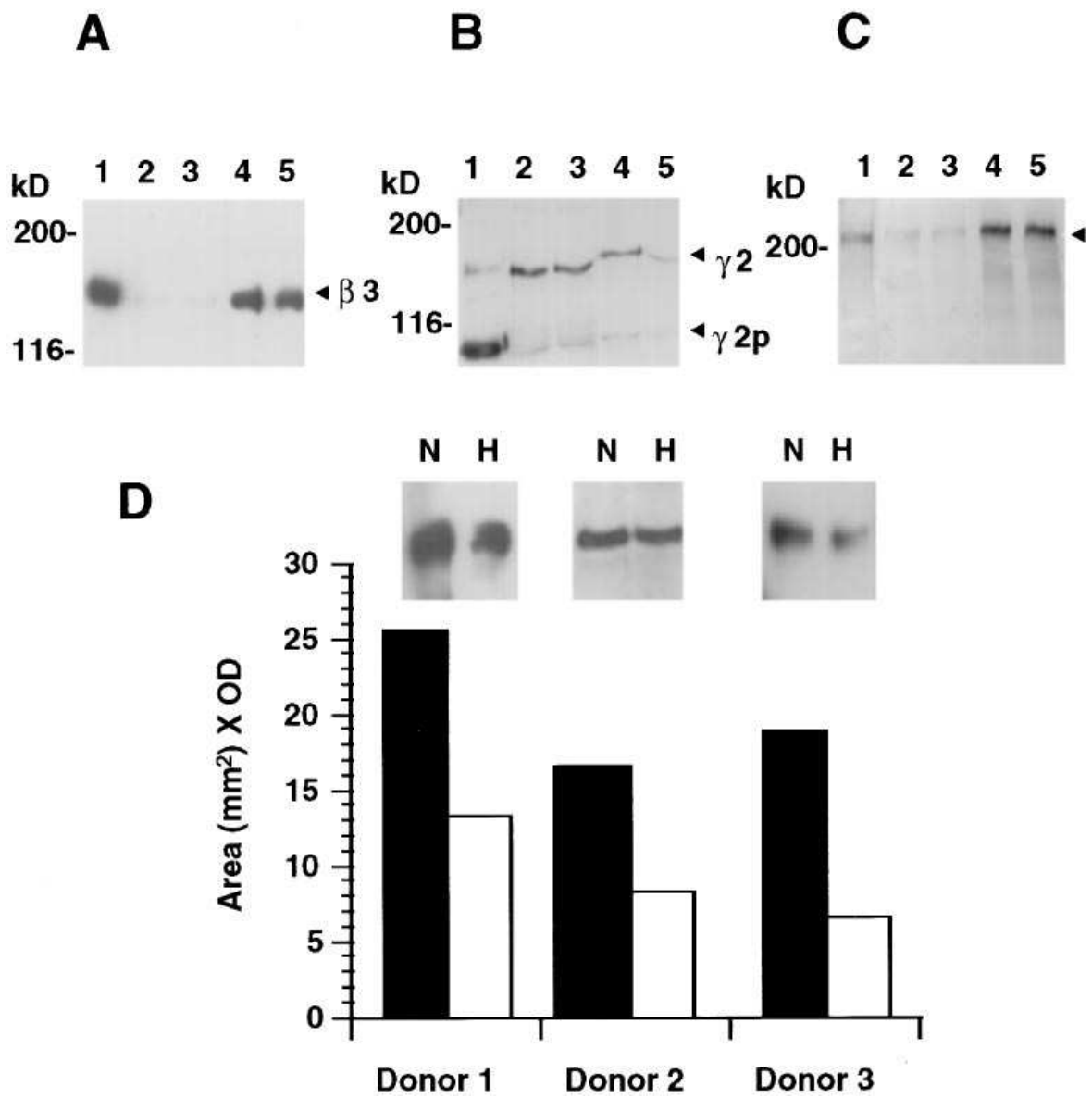

Figure 7. Western blot demonstrating laminin-5 and fibronectin synthesis under normoxic and hypoxic conditions. Neonatal keratinocytes were plated on plastic tissue culture dishes at a concentration of 17,500 cells $/ \mathrm{cm}^{2}$. The cells were incubated under normoxic and hypoxic conditions for $18 \mathrm{~h}$. The cells were extracted as described in the text. Equal amounts of protein were subjected to SDS-PAGE and Western blotting. $(A)$ The blotted proteins were labeled with an antibody to the $\beta 3$ chain of laminin-5 (140 kD). (B) The blotted proteins were labeled with an antibody to the $\gamma 2$ chain of laminin- $5(155 \mathrm{kD}$ processed to $105 \mathrm{kD}[\gamma 2 p]) .(C)$ The blotted proteins were labeled with an antibody to fibronectin $(220 \mathrm{kD})$. Lane 1 in each panel is the positive control. In each panel, lanes 2 and 3 are $2 \mathrm{M}$ urea extracts from normoxic and hypoxic conditions, respectively. In each panel, lanes 4 and 5 are the remaining extracellular matrix after serial extraction from normoxic and hypoxic conditions, respectively. Under hypoxic conditions secretion of the $\beta 3$ and $\gamma 2$ chains of laminin-5 is decreased, however fibronectin remains unchanged. Protein bands were quantitated by densitometry. $n=\mathrm{OD} \times$ area. $\beta 3$ chain: normoxic, $n=10.6$; hypoxic, $n=6.5$. $\gamma 2$ chain $(155 \mathrm{kD})$ : normoxic, $n=3.44$; hypoxic, $n=0.94$. Fibronectin: normoxic, $n=$ 7.828; hypoxic, $n=8.02$. (D) Laminin-5 $\gamma 2$ chain protein bands were quantitated by densitometry in three different experiments. Donors 1 and 2 (adult), donor 3 (neonatal). Solid bars, normoxia; clear bars, hypoxia. amounts of laminin-5 under normoxic conditions. This is visible as a sheet of irregular fluorescence (Fig. $8 \mathrm{~A}$ ). Under hypoxic conditions, the amount of laminin- 5 deposited by the keratinocyte is visibly diminished (Fig. $8 \mathrm{~B}$ ). The negative control slide, stained with mouse IgG, (Fig. $8 C$ ) demonstrated no fluorescent staining of the extracellular matrix.

Effect of hypoxia on keratinocyte EGF and integrin receptors. EGF and the EGF receptor play an important role in keratinocyte motility $(29,30,42)$. Likewise, cell surface receptors called integrins that recognize extracellular matrices play a crucial role in keratinocyte migration $(18,29,43,44)$. Therefore, we sought to determine if hypoxic conditions altered the expression of keratinocyte integrins or the expression of the EGF receptor. We examined the cells by FACS ${ }^{\circledR}$ analysis (29) under both normoxic and hypoxic conditions. No quantitative differences in these receptors were associated with hypoxia versus normoxia when the cells were opposed to a matrix that supports motility, i.e., collagen I. Although the $\alpha 3 \beta 1$ integrin plays a unique role in integrin-mediated keratinocyte migration and the $\alpha 6 \beta 4$ integrin induces keratinocyte adhesion to laminin-5 via hemi-desmosomes $(36,43)$, the enhanced migration of keratinocytes under hypoxic conditions cannot be explained by an alteration in integrin receptors. An EGF/TGF- $\alpha /$ EGF-receptor-mediated pathway is activated during human wound repair $(30,45)$, however this signaling pathway does not appear to be induced during hypoxia.

Effect of hypoxia on gelatinase B expression. Type I collagen (37), dibutryl cyclic AMP (46), and hepatocyte growth factor (47) increase keratinocyte migration in association with an increased expression of the $92-\mathrm{kD}$ type IV collagenase by the cells. Therefore, we sought to determine if hypoxia-driven enhancement of keratinocyte motility was associated with an alteration in the expression of keratinocyte-derived collagenases. The 72 - and the $92-\mathrm{kD}$ type IV collagenases were readily detectable in conditioned medium of keratinocytes under normoxic and hypoxic conditions by zymography and Western blotting. By densitometry analysis of both zymograms and Western blots, we found that keratinocytes under hypoxic conditions demonstrated a 1.5-2-fold enhanced synthesis of the 92-kD collagenase, whether plated on type I collagen or tissue culture plastic when compared with normoxic conditions (Fig. 9). As demonstrated in Fig. $9 A$, lanes 2 and 3 show the relative expressions of the $92-$ and the $72-\mathrm{kD}$ gelatinases secreted by human keratinocytes migrating on a matrix of type I collagen under normoxic (lane 2) and hypoxic (lane 3 ) conditions. When one compares lane 2 with lane 3 in Fig. 9, one notes an enhancement of the $92-\mathrm{kD}$ band corresponding to the $92-\mathrm{kD}$ gelatinase, while the $72-\mathrm{kD}$ bands, corresponding to the $72-\mathrm{kD}$ 

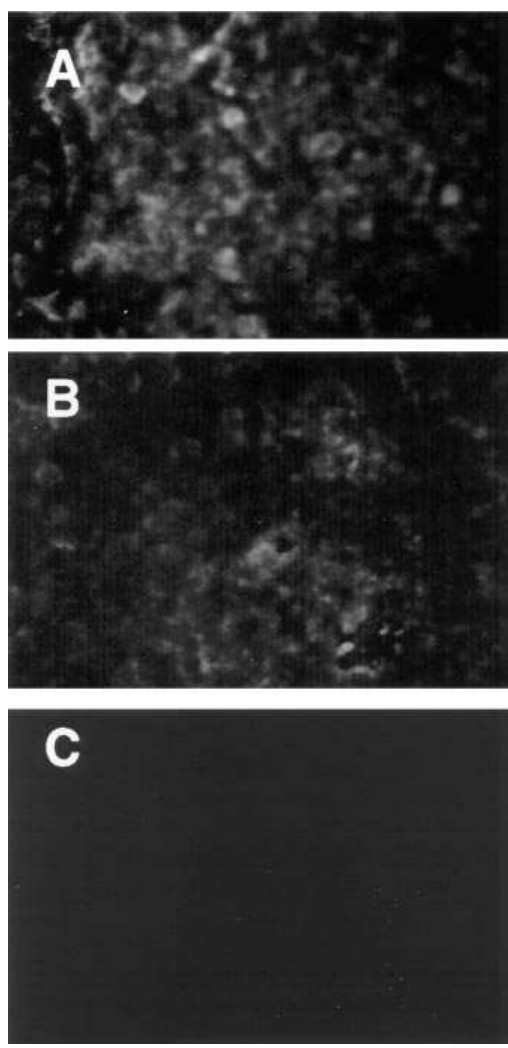

Figure 8. Immunostaining of keratinocyte extracellular matrix under normoxic and hypoxic conditions. Keratinocytes were cultured in TissueTek chamber slides (Nunc, Inc.) under normoxic and hypoxic conditions for $18 \mathrm{~h}$. The keratinocyte monolayers were extracted by serial extraction as described in the text and the remaining deposited extracellular matrix was stained with GB3 antibody for laminin-5, followed by a FITC-conjugated antibody. The cells were photographed with a Zeiss immunofluorescence microscope. $\times 92$. posed to a matrix. In contrast, the in vitro scratch assay measures the migration of a confluent sheet of keratinocytes over matrix. We found that hypoxia significantly enhanced keratinocyte motility on collagens and fibronectin compared with normoxic conditions. The pro-migratory effect of hypoxia is comparable in potency to soluble factors like EGF, TGF- $\alpha$, and IL- $1 \alpha(30,53)$. This result is counter to the notion that reduced oxygen tension has a negative effect on wound healing (3-5). While hypoxia may not be beneficial for overall wound healing, certain elements of the wound healing process such as re-epithelialization may be initiated and promoted by hypoxic conditions.

Occlusive dressings promote the early re-epithelialization of skin wounds $(8-12,13)$. Varghese et al. (15) demonstrated that the oxygen tension beneath occlusive dressings covering human skin wounds is very low, and yet these dressings promote re-epithelialization when used within the first $24 \mathrm{~h}$ after wounding (8-12,13). Ambient oxygen tension at the surface of chronic wounds without occlusive dressings has been measured and found to be $18-21 \mathrm{mmHg}(\sim 3 \%)(4,54)$. In contrast, the oxygen tension of the wound surface beneath semiocclusive wound dressings was found to be negligible (15). Therefore, semi-occlusive dressings promote hypoxic conditions at the wound surface where the advancing tongue of re-epithelializing keratinocytes is located. It is conceivable, then, that wound hypoxia induced by semiocclusive wound dressings may ex-

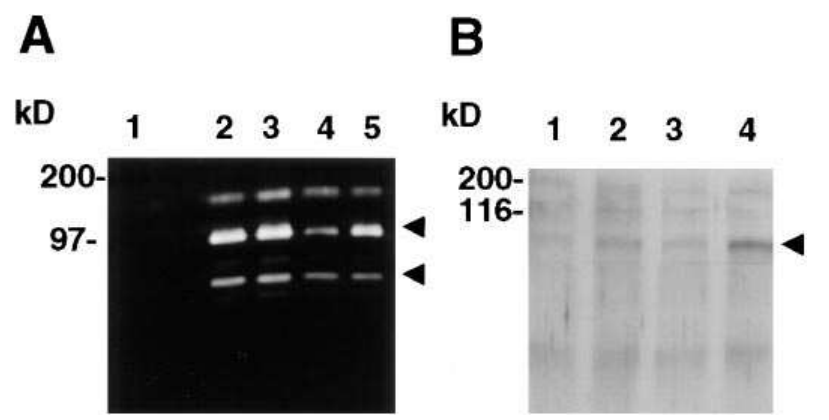

Figure 9. (A) A representative zymogram demonstrating secretion of the $72-\mathrm{kD}$ and the $92-\mathrm{kD}$ type IV collagenases under normoxic and hypoxic conditions. Gelatin zymography was performed on proteins from conditioned medium from migrating keratinocytes incubated under normoxic and hypoxic conditions on either a collagen I matrix (lanes 2 and 3) or no matrix (lanes 4 and 5). Note that the large prominent white band running just below the $97-\mathrm{kD}$ marker is increased in lanes 3 and 5 (hypoxic conditions) compared with lanes 2 and 4 (normoxic conditions). The 72-kD type IV collagenase is not altered by hypoxia. For the purpose of densitometry, a positive image of the zymogram in $A$ was prepared and the relative expression of the bands quantitated by densitometry. $n=\mathrm{OD} \times$ area. The values for the 92-kD band were 19.41 (lane 2 = normoxic cells on collagen); 26.98 (lane 3 = hypoxic cells on collagen); 12.39 (lane $4=$ normoxic cells on no matrix); and 20.67 (lane $5=$ hypoxic cells on no matrix). (B) Western blot of $92 \mathrm{kD}$ type IV collagenase of conditioned medium from keratinocyte cultures under normoxic and hypoxic conditions on no matrix (lanes 1 [normoxic] and 2 [hypoxic]) and collagen I (lanes 3 [normoxic] and 4 [hypoxic]). The relative expression of the bands was quantitated by densitometry. The values for the $92-\mathrm{kD}$ band were 0.71 (lane $1=$ normoxic cells on no matrix); 1.43 (lane $2=$ hypoxic cells on no matrix); 0.73 (lane $3=$ normoxic cells on collagen I); 1.88 (lane 4 = hypoxic cells on collagen I). 
plain why re-epithelialization is enhanced beneath this type of dressing. Acute hypoxia may be a potent, natural signal for the marginal keratinocytes to migrate out over the wound bed and cover the provisional matrix of fibronectin, fibrin, and collagen. Our finding that hypoxia promotes keratinocyte motility provides experimental justification for the clinical use of semi-occlusive wound dressings.

The mechanisms of keratinocyte motility are not known, but Odland and Ross (55) demonstrated that lamellipodia formation occurs when human keratinocytes become migratory during reepithelialization. Ezrin, moesin, and radixin are constitutive proteins involved in the formation of lamellipodia (32, 34). Recently, ezrin and moesin have been shown to bind to actin $(34,56)$. Moesin and radixin are upregulated in experimental glomerulonephritis during mesangial cell repair after injury and ezrin plays a role in hepatocyte growth factor-mediated migration in epithelial cells $(57,58)$. These data are the only evidence to date linking these cytoskeletal proteins to motility. In this study, we show that human keratinocytes stimulated to migrate by hypoxia exhibit increased expression of lamellipodia-associated proteins and redistribute them to the plasma membrane. To determine whether the alterations in ERM expression and distribution were hypoxia or motilityinduced, we examined these variables in confluent keratinocyte cultures held under normoxic and hypoxic conditions. Changes in the ERM proteins were not apparent (data not shown), suggesting that the changes seen in subconfluent cultures under hypoxic conditions are secondary to motility rather than hypoxia.

Laminin and laminin isoforms, such as laminin-5, inhibit human keratinocyte motility $(17,41)$. Laminin -5 is a powerful matrix attachment factor for human keratinocytes which mediates cell adhesion via integrins $\alpha 3 \beta 1$ in focal adhesions and $\alpha 6 \beta 4$ in hemidesmosomes $(36,40)$. In stable unwounded skin, the nonmigratory basal keratinocytes are resting on the lamina lucida, a 35-nm zone rich in laminin isoforms. In contrast to laminin isoforms, collagens and fibronectin in the wound bed provide keratinocytes with matrices that are known to strongly promote keratinocyte motility (59). In skin wounds, the reexpression of laminin within the neobasement membrane zone occurs at the time keratinocytes stop migrating (60). In this study, we found that hypoxic conditions induced a decreased expression of laminin-5 (Fig. 7). The inhibition of laminin-5 by hypoxia could conceivably perturb the keratinocytes' intrinsic motility brake, make the keratinocytes less anchored to their substratum, and allow the cells to exhibit enhanced motility.

Matrix receptors on cell surfaces, called integrins, have been shown to play central roles in human keratinocyte motility on connective tissue components $(18,29,39,44)$. Nevertheless, the enhanced keratinocyte migration induced by hypoxia cannot be explained by an altered expression of integrins or the EGF receptor since FACS ${ }^{\circledR}$ analysis demonstrated similar integrin profiles regardless of the oxygen tension. Changes in integrin receptor expression may not be required for the increase in migration induced by hypoxia. The increased motility may require redistribution or increased amounts of ERM proteins at the cortical membrane or changes in cell-substratum adhesion that could be achieved by differences in assembly/ disassembly of adhesion sites. Although, protein synthesis is unaltered by hypoxia, selective changes in protein expression could be secondary to a direct effect of hypoxia on transcription or mRNA stability and translation (61).
Another mechanism involved in cellular motility is the expression of metalloproteinases (62-66). We have shown previously that, like dermal fibroblasts, human keratinocytes synthesize and secrete type I and type IV collagenases $(37,65,66)$. Moreover, these collagenases exhibit increased expression when the keratinocytes are migrating $(37,65)$. A matrix of interstitial collagen induces keratinocyte motility and the expression of collagenases $(37,62-64)$. In this study, we show that keratinocytes induced to migrate by hypoxia exhibit an upregulation of the $92-\mathrm{kD}$ type IV collagenase while the $72-\mathrm{kD}$ type IV collagenase remains unaltered (Fig. 9). The increased activity of the $92-\mathrm{kD}$ collagenase under hypoxic conditions was apparent in conditioned medium from confluent and subconfluent keratinocyte cultures (data not shown) suggesting that hypoxia directly influences collagenase secretion. AP-1, a transcription factor important in collagenase production, is induced by hypoxia in endothelial cells (67). It is likely that the increased 92-kD collagenase activity observed in our study occurs by a similar mechanism. The role of collagenases in cell motility may be to degrade the endogenously synthesized matrix used by the cells for transient attachment, allow for cell-matrix disadhesion, and permit continued cellular motility.

Intuitively, one might consider hypoxic conditions unfavorable for wound healing. Hyperbaric oxygen and oximeters have been used to optimize the oxygenation of skin wounds (7). Nevertheless, the efficacy of such maneuvers is controversial. For example, we could find only one controlled study supporting the use of hyperbaric oxygen for chronic leg ulcers (68), while other studies suggested hyperbaric oxygen has little or no effect on wound healing $(69,70)$. In this study, we have shown that human keratinocytes migrating on connective tissue matrices exhibit enhanced motility when subjected to hypoxia. This observation is in accordance with the fact that keratinocytes at the margins of skin wounds are in a hypoxic environment and the observation that clinically-enhanced re-epithelialization occurs in skin wounds treated with semiocclusive dressings. Hypoxia may initiate human keratinocyte migration by several cellular mechanisms including $(a)$ the promotion of lamellipodia formation; $(b)$ the enhancement of collagenase expression that serves to allow for matrix disadhesion and continued migration; and (c) a decrease in cell-substratum attachment mediated by decreased expression of laminin-5, a potent matrix attachment factor for keratinocytes.

\section{Acknowledgments}

The work was supported by grants PO1 AR41045 (D.T. Woodley) and RO1 AR33625 (D.T. Woodley) from the National Institutes of Health, and a Dermatology Foundation Career Development Award and the Office of Research and Development, VA Palo Alto Health Care System (M.P. Marinkovich). E.A. O'Toole is a Howard Hughes Medical Institute Physician Postdoctoral Fellow.

\section{References}

1. Hunt, T.K. 1980. Wound Healing and Wound Infection: Theory and Surgical Practice. Appleton-Century-Crofts, New York. 303 pp.

2. Hunt, T.K. 1988. The physiology of wound healing. Ann. Emerg. Med. 17: 1265-1273.

3. Franzeck, U.K., P. Talke, E.F. Bernstein, F.L. Golbranson, and A. Fronek. 1982. Transcutaneous $\mathrm{PO}_{2}$ measurements in health and peripheral arterial disease. Surgery (St. Louis). 91:156-163.

4. Mani, R., J.E. White, D.F. Barrett, and P.W. Weaver. 1989. Tissue oxygenation, venous ulcers and fibrin cuffs. J. R. Soc. Med. 82:345-346. 
5. Conlon, K.C., L. Sclafani, G.R. DiResta, and M.F. Brennan. 1994. Comparison of transcutaneous oximetry and laser Doppler flowmetry as noninvasive predictors of wound healing after excision of extremity soft-tissue sarcomas. Surgery (St. Louis). 115:335-340.

6. Roth, R.N., and L.D. Weiss. 1994. Hyperbaric oxygen and wound healing. Clin. Dermatol. 12:141-156.

7. Nemeth, A.J., W.H. Eaglstein, and V. Falanga. 1989. Clinical parameters and transcutaneous oxygen measurements for the prognosis of venous ulcers. $J$. Am. Acad. Dermatol. 20:186-190.

8. Winter, G.D. 1962. Formation of the scab and the rate of epithelialization of superficial wounds in the skin of the young domestic pig. Nature. 193:293294.

9. Eaglstein, W.H. 1985. Experiences with biosynthetic dressings. J. Am. Acad. Dermatol. 12:434-440.

10. Falanga, V. 1988. Occlusive wound dressings. Arch. Dermatol. 124:872-877.

11. Alvarez, O.M., P.M. Mertz, and W.H. Eaglstein. 1983. The effect of occlusive dressings on collagen synthesis and re-epithelialization in superficial wounds. J. Surg. Res. 35:142-148.

12. Alper, J.C., E.A. Welch, M. Ginsberg, H. Bogaars, and P. Maguire. 1983. Moist wound healing under a vapor permeable membrane. J. Am. Acad. Dermatol. 8:347-353.

13. Eaglstein, W.H., S.C. Davis, A.L. Mehle, and P.M. Mertz. 1988. Optimal use of an occlusive dressing to enhance wound healing; effect of delayed application and early removal on wound healing. Arch. Dermatol. 124:392-395.

14. Niinikoski, J., F. Gottrup, and T.K. Hunt. 1991. The role of oxygen in wound repair. In Wound Healing. H. Janssen, R. Rooman, and J. Robertson, editors. Wrightson Biomedical Publishing, London. 165-174.

15. Varghese, M.C., A.K. Balin, D.M. Carter, and D. Caldwell. 1986. Local environment of chronic wounds under synthetic dressings. Arch. Dermatol. 122: $52-57$.

16. Woodley, D.T. 1996. Re-epithelialization. In The Molecular and Cellular Biology of Wound Repair, 2nd ed. R.A.F. Clark, editor. Plenum Publishing Corp., New York. 339-350.

17. Woodley, D.T., P.M. Bachmann, and E.J. O'Keefe. 1988. Laminin inhibits human keratinocyte migration. J. Cell. Physiol. 136:140-146.

18. Kim, J.P., K. Zhang, J.D. Chen, R.H. Kramer, and D.T. Woodley. 1992. Mechanism of human keratinocyte migration on fibronectin: unique role of RGD sites and integrins. J. Cell. Physiol. 151:443-450.

19. Boyce, S.T., and R.G. Ham. 1983. Calcium-regulated differentiation of normal human epidermal keratinocytes in chemically defined clonal culture and serum-free serial culture. J. Investig. Dermatol. 81(Suppl.):33S-40S.

20. O'Keefe, E.J., and M.L. Chiu. 1988. Stimulation of thymidine incorporation in keratinocytes by insulin, epidermal growth factor and placental extract: comparison with cell number to assess growth. J. Investig. Dermatol. 90:2-7.

21. Woodley, D.T., C.N. Rao, J.R. Hassell, L.A. Liotta, G.R. Martin, and H.K. Kleinman. 1983. Interactions of basement membrane protein components. Biochim. Biophys. Acta. 761:278-283.

22. Marinkovich, M.P., G.P. Lunstrum, and R.E. Burgeson. 1992. The anchoring filament protein kalinin is synthesized and secreted as a high molecular weight precursor. J. Biol. Chem. 267:17900-17906.

23. Wayner, E.A., and W.G. Carter. 1987. Identification of multiple cell adhesion receptors for type VI collagen and fibronectin in human fibrosarcoma cells possessing unique $\alpha$ and common $\beta$ subunits. J. Cell Biol. 105:1873-1884.

24. Wayner, E.A., W.G. Carter, R.S. Piotrowicz, and T.J. Kunicki. 1988. The function of extracellular matrix receptors in mediating cell adhesion to extracellular matrix: preparation of monoclonal antibodies to the fibronectin receptor that specifically inhibit cell adhesion to fibronectin and react with platelet glycoproteins Ic-IIa. J. Cell Biol. 107:1881-1891.

25. Wayner, E.A., A. Garcia-Pardo, M.J. Humphries, J.A. McDonald, and W.G. Carter. 1989. Identification and characterization of the T lymphocyte adhesion receptor for an alternative cell attachment domain in plasma fibronectin. J. Cell Biol. 109:1321-1330.

26. Carter, W.G., E.A. Wayner, T.S. Bouchard, and P. Kaur. 1990. The role of integrins $\alpha 2 \beta 1$ and $\alpha 3 \beta 1$ in cell-cell and cell-substrate adhesion of human epidermal cells. J. Cell Biol. 110:1387-1404.

27. Verrando, P., A. Pisani, and J.P. Ortonne. 1988. The new basement membrane antigen recognized by the monoclonal antibody GB3 is a large size weight glycoprotein; modulation of its expression by retinoic acid. Biochim. Biophys. Acta. 942:45-56.

28. Albrecht-Buehler, G. 1977. The phagokinetic tracks of 3 T3 cells. Cell. 11:395-404.

29. Chen, J.D., J.P. Kim, K. Zhang, Y. Sarret, K.C. Wynn, R.H. Kramer, and D.T. Woodley. 1993. Epidermal growth factor promotes human keratinocyte locomotion on collagen I by increasing the $\alpha 2$ integrin subunit. Exp. Cell Res. 209:216-223.

30. Cha, D., P. O'Brien, E.A. O'Toole, D.T. Woodley, and L.G. Hudson. 1996. Enhanced modulation of keratinocyte motility by TGF $\alpha$ relative to EGF. J. Investig. Dermatol. 106:590-597.

31. Lowry, O.H., N. Rosebrough, A.L. Farr, and R.J. Randall. 1951. Protein measurement with the Folin phenol reagent. J. Biol. Chem. 193:265-275.

32. Takeuchi, K., N. Sato, H. Kasahara, N. Funayama, A. Nagafuchi, S. Yonemura, S. Tsukita, and S. Tsukita. 1994. Perturbation of cell adhesion and microvilli formation by antisense oligonucleotides to ERM family members. $J$. Cell Biol. 125:1371-1384.

33. Towbin, H., T. Staehelin, and J. Gordon. 1979. Electrophoretic transfer of proteins from polyacrylamide gels to nitrocellulose sheets; procedure and some applications. Proc. Natl. Acad. Sci. USA. 76:4350-4354.

34. Pestonjamasp, K., M.R. Amieva, C.P. Strassel, W.M. Nauseef, H. Furthmayr, and E.J. Luna. 1995. Moesin, ezrin and p205 are actin-binding proteins associated with neutrophil plasma membranes. Mol. Biol. Cell. 6:247-259.

35. McLean, I.W., and P.K. Nakane. 1974. Periodate-lysine-paraformaldehyde fixative for immunoelectron microscopy. J. Histochem. Cytochem. 22: 1077-1083.

36. Carter, W.G., M.C. Ryan, and P.J. Gahr. 1991. Epiligrin, a new cell adhesion ligand for integrin $\alpha 3 \beta 1$ in epithelial basement membranes. Cell. 65 : 599-610.

37. Sarret, Y., D.T. Woodley, G.S. Goldberg, A. Kronberger, and K.C. Wynn. 1992. Constitutive synthesis of a $92 \mathrm{kDa}$ keratinocyte derived type IV collagenase is enhanced by type I collagen and decreased by type IV collagen matrices. J. Investig. Dermatol. 99:836-841.

38. Eisinger, M., J.S. Lee, J.M. Hefton, Z. Darzynkiewicz, J.W. Chiao, and E. de Harven. 1979. Human epidermal cell cultures: growth and differentiation in the absence of differentiation in the absence of dermal components or medium supplements. Proc. Natl. Acad. Sci. USA. 76:5340-5344.

39. Herrick, S.E., G.W. Ireland, D. Simon, C.N. McCollum, and M.W. Ferguson. 1996. Venous ulcer fibroblasts compared with normal fibroblasts show differences in collagen but not fibronectin production under both normal and hypoxic conditions. J. Investig. Dermatol. 106:187-193.

40. Baker, S.E., A.P. DiPasquale, E.L. Stock, V. Quaranta, M. Fitchmun, and J.C. Jones. 1996. Morphogenetic effects of soluble laminin-5 on cultured epithelial cells and tissue explants. Exp. Cell Res. 228:262-270.

41. O'Toole, E.A., M.P. Marinkovich, W.K. Hoeffler, H. Furthmayr, and D.T. Woodley. 1997. Laminin-5 inhibits keratinocyte motility. Exp. Cell Res. 233:330-339.

42. McCawley, L.J., P. O’Brien, and L.G. Hudson. 1997. Overexpression of the epidermal growth factor receptor contributes to enhanced ligand-mediated motility in keratinocyte cell lines. Endocrinology. 138:121-127.

43. Kim, J.P., K. Zhang, R.H. Kramer, T.J. Schall, and D.T. Woodley. 1992. Integrin receptors and RGD sequences in human keratinocyte migration unique anti-migratory function of the $\alpha 3 \beta 1$ epiligrin receptor. J. Investig. Dermatol. 98:764-770.

44. Kim, J.P., K. Zhang, J.D. Chen, R.H. Kramer, and D.T. Woodley. 1994 Vitronectin-driven human keratinocyte locomotion is mediated by the $\alpha \mathrm{V} \beta 5$ integrin receptor. J. Biol. Chem. 269:926-932.

45. Jensen, P.J., and U. Rodeck. 1993. Autocrine/paracrine regulation of keratinocyte urokinase plasminogen activator through the TGF-alpha/EGF receptor. J. Cell. Physiol. 155:333-339.

46. Iwasaki, T. J.D. Chen, J.P. Kim, K.C. Wynn, and D.T. Woodley. 1994. Dibutyryl cyclic AMP modulates keratinocyte migration without alteration of integrin expression. J. Investig. Dermatol. 102:891-897.

47. Dunsmore, S.E., J.S. Rubin, S.O. Kovacs, M. Chedid, W.C. Parks, and H.G. Welgus. 1996. Mechanisms of hepatocyte growth factor stimulation of keratinocyte metalloproteinase production. J. Biol. Chem. 271:24576-24582.

48. Ishibashi, H., K. Nakagawa, Y. Nakashima, and K. Sueishi. 1995. Conditioned medium of carcinoma cells cultured in hypoxic microenvironment stimulate angiogenesis in vitro; relationship to basic fibroblast growth factor. Virchows Arch. 425:561-568.

49. Koga, S., S. Ogawa, J. Leavy, R. Shreeniwas, M. Glauss, and D.M. Stern. 1991. Growth of hypoxic endothelial cells is stimulated by mitogens, in cluding bFGF, released by hypoxic macrophages. Thromb. Haemostasis. 65:757 (Abstr.).

50. Falanga, V., S.W. Qian, D. Danielpour, M.H. Katz, A.B. Roberts, and M.B. Sporn. 1991. Hypoxia up-regulates the synthesis of TGF- $\beta 1$ by human dermal fibroblasts. J. Investig. Dermatol. 97:634-637.

51. Yamamoto, T., N.A. Noble, D.E. Miller, and W.A. Border. 1994. Sustained expression of TGF- $\beta 1$ underlies the development of progressive kidney fibrosis. Kidney Int. 45:916-927.

52. Mustoe, T.A., G.F. Pierce, A. Thomason, P. Gramates, M.B. Sporn, and T.F. Deuel. 1987. Accelerated healing of incisional wounds in rats induced by TGF-beta. Science. 237:1333-1336.

53. Chen, J.D., J.C. Lapiere, D.N. Sauder, C. Peavey, and D.T. Woodley. 1995. Interleukin- $\alpha$ stimulates keratinocyte migration through an EGF/TGF $\alpha$-independent pathway. J. Investig. Dermatol. 104:729-733.

54. Falanga, V., A. McKenzie, and W.H. Eaglstein. 1991. Heterogeneity in oxygen diffusion around venous ulcers. J. Dermatol. Surg. Oncol. 17:336-339.

55. Odland, G., and R. Ross. 1968. Human wound repair. I. Epidermal regeneration. J. Cell Biol. 39:135-151.

56. Algrain, M., O. Turenen, A. Vaheri, D. Louvard, and M. Arpin. 1993. Ezrin contains cytoskeleton and membrane binding domains accounting for its proposed roles as a membrane-cytoskeletal linker. J. Cell Biol. 120:129-139.

57. Hugo, C., C. Hugo, R. Pichler, K. Gordon, R. Schmidt, M.R. Amieva, W.G. Couser, H. Furthmayr, and R.J. Johnson. 1996. The cytoskeletal linking proteins, moesin and radixin, are upregulated by platelet-derived growth factor, but not basic fibroblast growth factor in experimental mesangial proliferative 
glomerulonephritis. J. Clin. Invest. 97:2499-2508.

58. Crepaldi, T., A. Gautreau, P.M. Comoglio, D. Louvard, and M. Arpin. 1997. Ezrin is an effector of hepatocyte growth factor-mediated migration and morphogenesis in epithelial cells. J. Cell Biol. 138:423-434.

59. O'Keefe, E.J., R.E. Payne, N. Russell, and D.T. Woodley. 1985. Spreading and enhanced motility of human keratinocytes on fibronectin. J. Investig. Dermatol. 85:125-130.

60. Clark, R.A.F., J.M. Lanigan, P. Dellapelle, E. Manseau, H.F. Dvorak, and R.B. Colvin. 1982. Fibronectin and fibrin provide a provisional matrix for epidermal cell migration during wound re-epithelialization. J. Investig. Dermatol. 79:264-269.

61. Helfman, T., and V. Falanga. 1993. Gene expression in low oxygen. Am. J. Med. Sci. 306:37-41.

62. Inoue, M., G. Kratz, A. Haegerstrand, and M. Ståhle-Bäckdahl. 1995. Collagenase expression is rapidly induced in wound-edge keratinocytes after acute injury in human skin, persists during healing, and stops at re-epithelialization. J. Investig. Dermatol. 104:479-483.

63. Saarialho-Kere, UK, S.O. Kovacs, A.P. Pentland, J.E Olerud, H.G. Welgus, and W.C. Parks. 1993. Cell-matrix interactions modulate interstitial collagenase expression by human keratinocytes actively involved in wound healing. J. Clin. Invest. 92:2858-2866.
64. Pilcher, B.K,. J.A. Dumin, B.D. Sudbeck, S.M. Krane, H.G. Welgus, and W.C. Parks. 1997. The activity of collagenase-1 is required for human keratinocyte migration on a type I collagen matrix. J. Cell Biol. 137:1445-1457.

65. Petersen, M.J., D.T. Woodley, G.P. Stricklin, and E.J. O'Keefe. 1990. Enhanced synthesis of collagenase by human keratinocytes cultured on type I or type IV collagen. J. Investig. Dermatol. 94:341-346.

66. Woodley, D.T., T. Kalabec, A.J. Banes, W. Link, M. Prunieras, and L. Liotta. 1986. Adult human keratinocytes migrating over non-viable dermal collagen produce collagenolytic enzymes that degrade type I and type IV collagen. J. Investig. Dermatol. 86:418-423.

67. Bandyopadhyay, R.S., M. Phelan, and D.V. Faller. 1995. Hypoxia induces AP-1-regulated genes and AP-1 transcription factor binding in human endothelial and other cell types. Biochim. Biophys. Acta. 1264:72-78.

68. Hammarlund, C., and T. Sundberg. 1994. Hyperbaric oxygen reduced size of chronic leg ulcers: a randomized double-blind study. Plast. Reconstr. Surg. 93:829-833.

69. Caffee, H.H., and T.J. Gallagher. 1988. Experiments on the effects of hyperbaric oxygen on flap survival in the pig. Plast. Reconstr. Surg. 81:751-754.

70. Kulonen, E., and J. Niinikoski. 1968. Effect of hyperbaric oxygenation on wound healing and experimental granuloma. Acta Physiol. Scand. 73:383-384. 